\title{
Conversion of Erythrinane into Erythroidine Skeleton
}

\author{
Takeshi Kitahara and Masanao Matsui \\ Laboratory of Pesticides Synthesis II, The Institute of Physical and \\ Chemical Research, Wako-shi, Saitama
}

Received September 3, 1973

\begin{abstract}
Synthesis of erythroidine skeleton, containing $\beta, \gamma$-unsaturated- $\delta$-lactone system derived from erythrinane skeleton was described.
\end{abstract}

Erythrina alkaloids, occurring in the seeds and plant parts of Erythrina species, cause the paralysis of smooth muscles similar to the effect of curare. ${ }^{1 \sim 3)}$ Cocculolidine has an insecticidal activity. ${ }^{4}$. The alkaloids are derived into two groups according to their structural features; the one includes erythrinanes such as erysodine (I) and erythraline (II) which have a tetracyclic system in which D ring is aromatic, and the other includes Dring unsaturated $\delta$ - or $\gamma$-lactonic erythroidines (III) and cocculolidine (IV).

The synthesis of erythrina alkaloids has been investigated by many groups. Belleau and the schools of Wiesner, Prelog, Mondon, Rapoport and Scott have achieved significant successes.

Mondon succeeded in the synthesis of

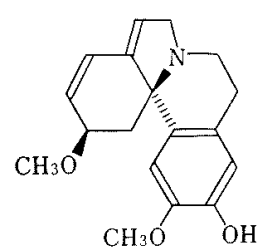

I
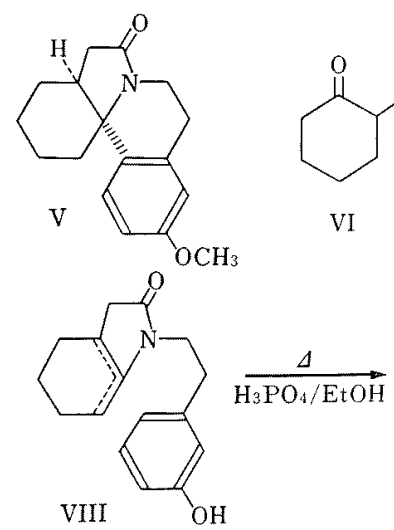

VI

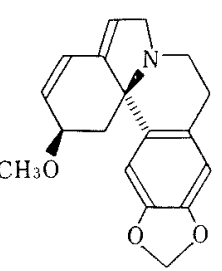

II

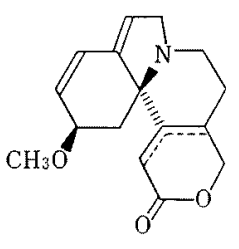

III

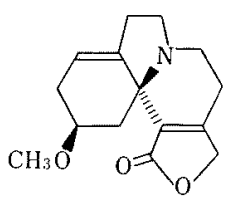

IV

FIG. A.

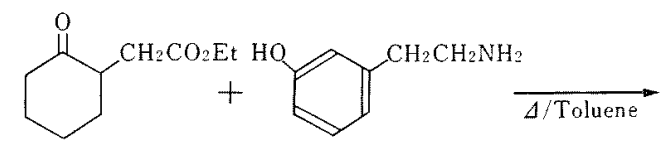

VII

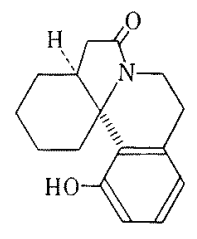

IX

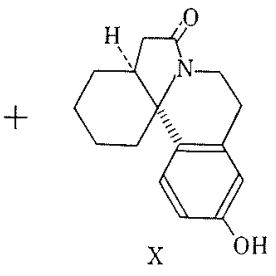

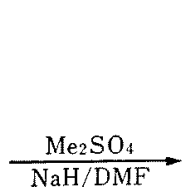

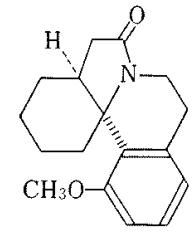

FIG. B. 
erysotrine (O-methyl erysodine $)^{5}$ and a naturally occurring alkaloid, dihydroerysodine ${ }^{6)}$ via oxidative coupling. ${ }^{7)}$ Frank et al. $^{87}$ also accomplished the synthesis of erythrinadienone of a biogenetic type ${ }^{9)}$ development of this field has been reviewed in details. ${ }^{10 \sim 16)}$

The syntheses of erythroidines and cocculolidine have not been accomplished yet. Recently Umezawa et al. ${ }^{17)}$ reported the synthesis of an erythroidine-type compound from erythrinane. The synthesis of the erythroidine system has also been studied by our group. We wish to describe the conversion of erythrinane to the erythroidine skeleton containing a $\beta, \gamma$-unsaturated $\delta$-lactone system in D-ring.

As a starting material was used 8-oxo-16methoxy erythrinane derived from ethyl 2oxo-cyclohexyl acetate (VI) and 2-( $m$-hydroxyphenyl) ethylamine (VII). Pyrolysis of the keto-ester (VI) with the amine (VII) in toluene gave a crude en-lactam (VIII) as an oily product which without purification was submitted to cyclization by treating with phosphoric acid in ethanol to afford a mixture of tetracyclic lactam phenols (IX, X) which can be separated by silica gel chromatography. However, without separation, the mixture was directly methylated with dimethyl sulfate and

sodium hydride to give two products in good yield separated by silica gel chromatography. First fraction contained a minor product (about $20 \%$ of the mixture), 8-oxo-14-methoxyerythrinane (XI), and a major one $(80 \%$ of the mixture), the starting material (V).

The birch reduction of the lactam (V) and the subsequent hydrolysis of the resulting enol ether with methanolic hydrogen chloride gave a conjugated enone (XII) in $62 \sim 71 \%$ yield. The aldol condensation of the enone (XII) with benzaldehyde in the presence of a catalytic amount of piperidine acetate at $80^{\circ} \mathrm{C}$ in benzene afforded its benzylidene derivative (XIII), isolated as a sole product by silica gel chromatography in $63 \%$ yield, $\mathrm{mp} 185.5 \sim$ $187^{\circ} \mathrm{C}$. UV and NMR data supported that a benzylidene group was introduced at $\mathrm{C}_{15^{-}}$ position as expected.

Other possible structures (XVII, XVIII) were excluded by these analytical data.

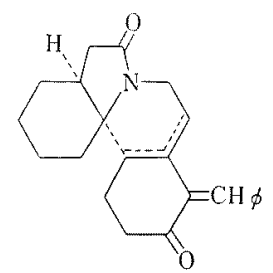

XVII

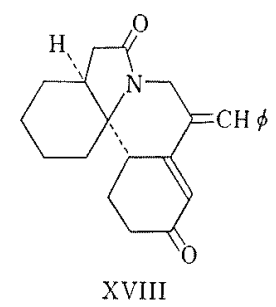

FIG. D.

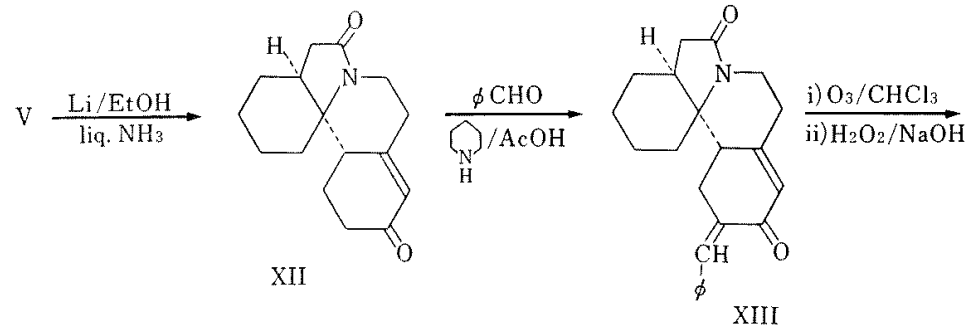

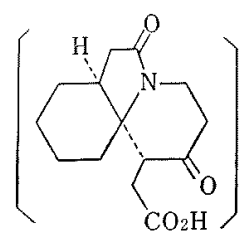

XIV

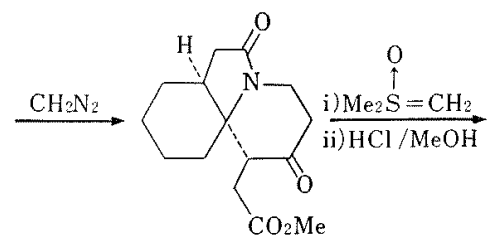

XV

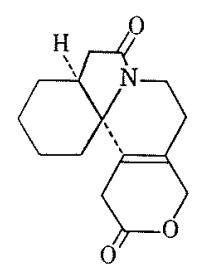

XVI

FIG. C. 
The benzylidene derivative (XIII) was ozonized in $\mathrm{CHCl}_{3}$ at $-20 \sim 30^{\circ} \mathrm{C}$ and the resulting ozonide was oxidized with alkaline-hydrogen peroxide at $0 \sim 5^{\circ} \mathrm{C}$ to a clude acid (XIV) which immediately esterified with diazomethane to afford a keto-ester (XV) as an oily product. To obtain the final product from the ketoester (XV), Corey's method of epoxide-synthesis $^{18)}$ was employed. The keto ester was treated with methyl oxosulfonium methylide in dimethyl sulfoxide ${ }^{19)}$ and successively with methanolic hydrogen chloride to afford a final product, 3-demethoxy-8-oxo-tetrahydro $\beta$-erythroidine (XVI). The structure of the final product was supported by physical data. Thus we have accomplished the synthesis of the erythroidine skeleton starting from erythrinane system. The synthesis of cocculolidine system is now under investigation.

\section{EXPERIMENTAL}

All mps were uncorrected.

14- and 16-Hydroxy-8-oxo-erythinane $(X I, X)$

A mixture of $m$-hydroxyphenethylamine $(6.8 \mathrm{~g})$ and ethyl 2-oxo-cyclohexylacetate $(9.2 \mathrm{~g})$ in toluene $(50 \mathrm{ml})$ was refluxed for $7 \mathrm{hr}$. The solvent was removed in vacuo and the resulting yellow brown oil was dissolved in $85 \%$ phosphoric acid $(30 \mathrm{ml})$ and $99 \%$ ethanol $(120 \mathrm{ml})$. After the mixture was refluxed for $7 \mathrm{hr}$, the solvent was removed in vacuo and the residual oil was poured into cold water, extracted with methylene chloride $(50 \mathrm{ml} 5)$. The extract was washed with water and dried over magnesium sulfate $\left(\mathrm{MgSO}_{4}\right)$. The solvent was distilled off and the resulting oil $(14.6 \mathrm{~g})$ was a mixture of two products. The main product was obtained by silica gel chromatography. mp $282^{\circ} \mathrm{C}$, colorless prisms. IR $v_{\max }^{\mathrm{KBr}} \mathrm{cm}^{-1}: 3200,1660$, 1580, Anal. Found: C, 74.65; H, 7.47; N, 5.45. Calcd. for $\mathrm{C}_{16} \mathrm{H}_{19} \mathrm{NO}_{2}: \mathrm{C}, 74.68 ; \mathrm{H}, 7.44 ; \mathrm{N}, 5.44$. The mixture of the two products was submitted to successive reactions without purfication.

\section{8-0xo-14-methoxyerythrinane (XI) and 8-0xo-16- methoxyerythrinane $(V)$}

To a solution of the crude lactam phenol $(14.6 \mathrm{~g})$ in $120 \mathrm{ml}$ anhydrous DMF, 50\% sodium hydride $(3.6 \mathrm{~g})$ was added portionwise, and to this, dimethyl sulfate $(9.8 \mathrm{~g})$ was added dropwise in a period of $20 \mathrm{~min}$ at $40 \sim 50^{\circ} \mathrm{C}$. After the addition was completed, the mixture was stirred at $80 \sim 90^{\circ} \mathrm{C}$ under a introgen atmosphere for $4 \mathrm{hr}$. The reaction mixture was cooled to r.t., poured into cold water and extracted with $\mathrm{CHCl}_{3}$ $(50 \mathrm{ml} \times 5)$ successively. The extract was washed with water and dried over $\mathrm{MgSO}_{4}$. Evaporation of the solvent afforded a mixture of two methyl ethers as an yellowbrown oil $(15.3 \mathrm{~g})$. Silica gel chromatography gave two main products. The first fraction, eluted by $\mathrm{CHCl}_{3} / \mathrm{Et}_{2} \mathrm{O}=9 / 1$, is 8-oxo-14-methoxyerythrinane $(\mathrm{XI}) \mathrm{mp} 102 \sim 103^{\circ} \mathrm{C}$, yield $1.92 \mathrm{~g}(14.2 \%)$ IR $\nu_{\mathrm{max}}^{\mathrm{KBr}} \mathrm{cm}^{-1}: 1678,1600$ (weak), 1580 (strong), 1258. NMR $\delta$ ppm: $1.20 \sim 3.20$ (methylene proton), 3.87 ( $3 \mathrm{H}$, singlet, $\left.-\mathrm{OCH}_{3}\right), 6.64 \sim 6.80(2 \mathrm{H}, 2 \times$ double doublet, $\mathrm{C}_{15}$ and $\left.\mathrm{C}_{17}-\mathrm{H}\right), 7.06 \sim 7.22(1 \mathrm{H}$, double doublet, $\left.\mathrm{C}_{16}-\mathrm{H}\right)$. Anal. Found: C, 75.15; H, 7.79; N, 4.98. Calcd. for $\mathrm{C}_{17} \mathrm{H}_{21} \mathrm{NO}_{2} ; \mathrm{C}, 75.24 ; \mathrm{H}, 7.80 ; \mathrm{N}, 5.16 \%$. The major one, obtained as the second fraction in $59.3 \%$ yield $(8.01 \mathrm{~g})$, is 8-oxo-16-methoxyerythrinane (V), mp $106 \sim 107^{\circ} \mathrm{C} . \quad$ IR $\psi_{\max }^{\mathrm{KBr}} \mathrm{cm}^{-1}: 1678,1605$ (strong), 1575 (weak), 1500, 1240. NMR $\delta$ ppm: $1.40 \sim 3.50$ (methylene proton), $3.83(3 \mathrm{H}$, singlet, $\left.-\mathrm{OCH}_{3}\right), 6.70\left(1 \mathrm{H}\right.$, doublet, $\left.J_{17-15}=2.5 \mathrm{~Hz}, \mathrm{C}_{17}-\mathrm{H}\right)$, $6.81\left(1 \mathrm{H}\right.$, double doublet, $J_{15-14}=8.5 \mathrm{~Hz}, J_{15-17}=$ $\left.2.5 \mathrm{~Hz}, \mathrm{C}_{15}-\mathrm{H}\right) 7.34\left(1 \mathrm{H}\right.$, doublet, $J_{14-15}=8.5 \mathrm{~Hz}$, $\left.J_{14-17} \sim 0, \mathrm{C}_{14}-\mathrm{H}\right)$. Anal. Found: C, 74.92; H, $7.83 ; \mathrm{N}, 4.89$. Calcd. for $\mathrm{C}_{17} \mathrm{H}_{21} \mathrm{NO}_{2}: C, 75.24$; $\mathrm{H}, 7.80 ; \mathrm{N}, 5.16$.

\section{8, 16-Dioxo-13, 14, 15, 16-tetrahydro erythrinane (XII)}

To a stirred solution of the methyl ether $(\mathrm{V}, 10 \mathrm{~g})$ and anhydrous ethanol $(50 \mathrm{ml})$ in liquid ammonia $(700 \mathrm{ml})$, lithium $(7.8 \mathrm{~g})$ was added in small pieces during a period of $30 \mathrm{~min}$. After the addition was completed, the mixture was stirred for additional $15 \mathrm{~min}$, and excess ammonium chloride was added to stop the reaction. Ammonia was evaporated and the residual oil was treated with methanolic $\mathrm{HCl}(5 \%$ soln.) and extracted with $\mathrm{CHCl}_{3}(50 \mathrm{ml} \times 5)$. The extract was washed with dilute sodium bicarbonate and water and dried over $\mathrm{MgSO}_{4}$. The solvent was removed to give an enone (XII) in $72 \%$ yield $(6.9 \mathrm{~g})$, colorless prism, mp $140 \sim 140.5^{\circ} \mathrm{C}$, recrystallized from $n$-propyl alcohol. UV $\lambda_{\max }^{\mathrm{gtCH}}: 251 \mathrm{~nm}, \varepsilon=11300 \mathrm{IR} \nu_{\max }^{\mathrm{KRr}} \mathrm{cm}^{-1}$ : $1680,1665,1610$. NMR $\delta \mathrm{ppm}: 6.02(1 \mathrm{H}$, singlet(small coupling with allylic methylene) olefinic proton). Anal. Found: C, 74.18; H, 8.14; N, 5.24. Calcd. for $\mathrm{C}_{16} \mathrm{H}_{21} \mathrm{NO}_{2} ; \mathrm{C}, 74.10 ; \mathrm{H}, 8.16 ; \mathrm{N}, 5.40$.

\section{5-Benzylidene-8, 16-dioxo-13, 14, 15, 16-tetrahydro- erythrinane $(X I I)$}

To a solution of piperidine $(400 \mathrm{mg})$, acetic acid $(260 \mathrm{mg})$ and the enone (XII, $2.0 \mathrm{~g}$ ) in anhydrous benzene $(80 \mathrm{ml})$, benzaldehyde $(880 \mathrm{mg})$ in benzene $(20 \mathrm{ml})$ was added at once, and the mixture was refluxed with stirring under a nitrogen atmosphere for $7 \mathrm{hr}$. The reaction mixture was poured into water and extracted with $\mathrm{CHCl}_{3}$. The extract was washed with dilute hydrochloric acid, water, a dilute sodium bicarbonate 
solution and water successively and dried over $\mathrm{MgSO}_{4}$. The solvent was removed and ether $(10 \mathrm{ml})$ was added to the residue to afford a benzylidene derivative (XIII), as yellow crystals $(528 \mathrm{mg})$. Silica gel chromatography $\left(\mathrm{CHCl}_{3}: \mathrm{Et}_{2} \mathrm{O}=15: 1\right)$ of the residual oil $(2.16 \mathrm{~g})$ to afford another crop $(795 \mathrm{mg})$. The starting material $(180 \mathrm{mg})$ was recovered as a second fraction. The total yield of the benzylidene derivative was $55 \%$. Physical data are as follows. $\mathrm{mp} 185.5 \sim 186.5^{\circ} \mathrm{C}$, recrystallized from $n$-ProOH. UV $\lambda_{\max }^{\mathrm{EtOH}}: 307 \mathrm{~nm}$, $\varepsilon=8820$. IR $\nu_{\max }^{\mathrm{K} \mathrm{Br}} \mathrm{cm}^{-1}: 1680,1675$ (shoulder), 1650 , 1638, 1595, 1585. NMR ô ppm: $5.84(1 \mathrm{H}$, broad singlet, olefinic proton). $7.2 \sim 7.6(6 \mathrm{H}$, aromatic proton, $\mathrm{C}_{6} \mathrm{H}_{5} \mathrm{CH}-$ ). Anal. Found: C, 79.26; H, 7.39; N, 3.78. Calcd. for $\mathrm{C}_{23} \mathrm{H}_{25} \mathrm{NO}_{2} ; \mathrm{C}, 79.50 ; \mathrm{H}, 7.25 ; \mathrm{N}, 4.03$.

\section{3-Demethoxy-y-oxo-tetrahydro- $\beta$-erythroidine $(X V I)$}

The benzylidene derivative (XIII, $700 \mathrm{mg}$ ) in $\mathrm{CHCl}_{3}$ $(50 \mathrm{ml})$ was ozonized at $-20 \sim-30^{\circ} \mathrm{C}$, and the resulting ozonide was treated with alkaline hydrogen peroxide, prepared from $30 \% \mathrm{H}_{2} \mathrm{O}_{2}(2 \mathrm{ml})$ and $5 \%$ $\mathrm{NaOH}(30 \mathrm{ml})$, at $0^{\circ} \mathrm{C}$ for $90 \mathrm{~min}$. The aqueous layer was acidified and extracted with $\mathrm{CHCl}_{3}$ repeatedly. The extract was dried over $\mathrm{MgSO}_{4}$, and was treated with excess diazomethane to give a crude product. Silica gel chromatography $\left(\mathrm{CHCl}_{3} / \mathrm{Et}_{2} \mathrm{O}=10 / 1\right)$ afforded an oily keto-ester, (XV, $246 \mathrm{mg}), \mathrm{IR} \nu_{\text {max }}^{\mathrm{flm}} \mathrm{cm}^{-1}$ : 1735, 1720 (shoulder), $1680 \mathrm{~cm}^{-1}$, NMR $\hat{o} \mathrm{ppm} ; 3.86$ (s, 3H, - $\mathrm{OCH}_{3}$ ). The keto-ester (XV, $168 \mathrm{mg}$ ) was treated with dimethyl oxosulfonium methylide $(1.5$ Meq), prepared as described in reference, from trimethyl sulfoxonium iodide $(197 \mathrm{mg})$ and methyl sulfinyl carbanion derived from $65 \%$ sodium hydride (36 mg) and anhydrous dimethyl sulfoxide $(10 \mathrm{ml})$. The reaction was carried out under a nitrogen atmosphere at room temperature for $24 \mathrm{hr}$. The reaction mixture was poured into dilute hydrochloric acid and extracted with $\mathrm{CHCl}_{3}(30 \mathrm{ml} \times 8)$. The extract was washed with water and dried over $\mathrm{MgSO}_{4}$. Evaporation of the solvent gave a crude yellowish oil. The oil was treated with methanolic hydrochloric acid (2\% solution) at room temperature for $24 \mathrm{hr}$. The solvent was removed in vacto and the residue was diluted with water and then extracted with $\mathrm{CHCl}_{3}$ $(50 \mathrm{ml} 5)$. The extract was washed with water and dried over $\mathrm{MgSO}_{4}$. The solvent was removed in vacuo to give a crude product. Silica gel chromatography $\left(\mathrm{CHCl}_{3} / \mathrm{Et}_{2} \mathrm{O}=15 / 1\right)$ afforded 3-demethoxy-8-oxotetrahydroerythroidine as colorless crystals $(64 \mathrm{mg}$ ), mp $155 \sim 156^{\circ} \mathrm{C} \quad$ IR $\nu_{\text {max }}^{\mathrm{KBr}} \mathrm{cm}^{-1}: 1725,1685,1620$. NMR $\delta \mathrm{ppm} ; 4.65$ (2H, singlet). Anal. Found: C, $68.89 ; \mathrm{H}, 7.25 ; \mathrm{N}, 5.34$. Calcd. for $\mathrm{C}_{15} \mathrm{H}_{19} \mathrm{NO}_{3} ; \mathrm{C}$, $68.94 ; \mathrm{H}, 7.33 ; \mathrm{N}, 5.36$.

\section{REFERENCES}

1) K. Unna, M. Kniazuk and J. G. Greslin, J. Pharmacol. Exp. Therap., 80, 39 (1944).

2) D. Megirian, D. E. Leary and I. H. Slater, ibid., 113, 212 (1955).

3) H. Lüllmann, A. Mondon and P. R. Seidel, Arch. Exp. Pathol. Pharmakol., 258, 91 (1967).

4) a) K. Wada, S. Marumo and K. Munakata, Tetrahedron Lett., 1966, 5179.

b) K. Wada and K. Munakata, Agr. Biol. Chem., 31, 336 (1967).

5) A. Mondon and H. J. Nestler, Angew. Chem., 76, 651 (1964).

6) A. Mondon and M. Ehrhardt, Tetrahedron Lett., 1966, 2557.

7) J. E. Gervey, F. McCapra, T. Money and A. I. Scott, Chem. Commun., 1966, 142.

8) B. Frand and V. Teetz, Angew. Chem., 83, 409 (1971).

9) D. H. R. Barton, R. James, G. W. Kirby, D. W. Turnar and D. A. Widdowson, J. Chem. Soc. (C), 1968, 1529.

10) L. Marion, Alkaloids, 2, $499 \sim 511$ (1952).

11) V. Boekelheide and V. Prelog, "Progress in Organic Chemistry," Vol. 3, Butterworths, London, England, 1955, pp. 218 266 .

12) V. Prelog, Angew. Chem., 69, 33 (1957).

13) V. Boekelheide, Alkaloids, 7, $201 \sim 227$ (1960).

14) H. G. Boit, "Ergebnisse der Alkaloid-Chemie bus 1960," Alkademie-Verlag, Berlin, Germany, 1961, pp. 383 401.

15) R. K. Hill, Alkaloids, 9, 483 515 (1967),

16) A. Mondon, "Chemistry of the Alkaloids," pp. 173 198; "Erythrina alkaloids," Van Nosland Reinhold, New York, U.S.A. 1970.

17) F. Umezawa, O. Hoshino and T. Okazaki, Abstract of Papers, the 93rd Meeting of Nippon Yakugakukai, Tokyo, 1973.

18) E. J. Corey and M. Chaykovsky, J. Amer. Chem. Soc., 87, 1353 (1965).

19) J. Blake, J. R. Tretter, G. J. Juhasz, W. Bonthrone and H. Rapoport, ibid., 88, 4061 (1966). 